\title{
HIGHLY ISOXANTHOHUMOL ENRICHED HOP EXTRACT OBTAINED BY \\ PRESSURIZED HOT WATER EXTRACTION (PHWE). CHEMICAL AND \\ FUNCTIONAL CHARACTERIZATION.
}

Alicia Gil-Ramírez; José Antonio Mendiola ; Elena Arranz ; Alejandro RuízRodríguez ; Guillermo Reglero ; Elena Ibáñez; Francisco R Marín ${ }^{\text {a* }}$

a Department of Characterization and production of New Foods. ${ }^{b}$ Department of Bioactivity and Food Analysis. Institute of Food Science Research (CIAL), (Spanish National Research Council-Universidad Autónoma de Madrid), C/Nicolás Cabrera, 9. Campus de la Universidad Autónoma de Madrid, 28049 Madrid, Spain.

* Corresponding author: francisco.marin@uam.es +34910017921 


\begin{abstract}
Hop (Humulus lupulus) is one of the richest natural sources of a prenylfalvonoids such as xanthohumol (XN), desmetylxanthohumol (DMX), isoxanthohumol (IX) or 8prenylnaringenin $(8-\mathrm{PN})$, being $\mathrm{XN}$ the most abundant of them in the raw material. So far, obtention of prenylflavonoids have been done by chemical synthesis or extraction with organic solvents, with no described methods for the isolation of IX, which has been reported to have anti-inflammatory properties. In this study, pressurized hot water extraction (PHWE) it is shown not only as effective method to extract some prenylflavonoids but to selectively change the relative amount of them, favoring the extraction of IX against XN. Thus, pressurized water extraction at $150^{\circ} \mathrm{C}$ showed a high selectivity towards IX, being proposed as a method to enrich natural hop's extracts in IX. On the other hand, the extracts thus obtained were chemically characterized and evaluated for their anti-inflammatory activity, which was higher than the expected by its content in IX.
\end{abstract}

KEYWORDS: Prenylflavonoids, xanthohumol (XN), isoxanthohumol (IX), Pressurized Hot Water Extraction (PHWE), anti-inflamatory. 


\section{INTRODUCTION}

Hop (Humulus lupulus L) cones have been used worldwide, including Native American tribes, European, Indian and Chinese cultures, and from prehistoric periods, for medicinal purposes, such as the treatment of sleeping and nervous disorders, as mild sedative, for the activation of gastric functions as bitter stomachic; besides its use in brewing since the early Middle Ages, in Europe (Zanoli, P. \& Zavatti, M. 2008).

The phytochemistry of hop is complex and includes, as main structural classes of chemicals, compounds identified as terpenes, bitter acids, chalcones, flavonol glycosides and catechins as more relevant ones (Chadwick, L.R. et al. 2006). Terpenes and bitter acids can represent up to $20 \%$ of hop strobile weight, with a high diversity and chemical complexity, and are associated with the brewing uses of hop. Besides the former, flavonoids and particularly prenylflavonoids are reported as responsible of interesting pharmacological properties such as estrogenic activity (Zanoli, P. \& Zavatti, M. 2008; Stevens, J.F. \& Page, J.E. 2004) and cancer-related bioactivities (Colgate, E.C. et al. 2007; Koo, J.H. et al. 2008) among others (Zanoli, P. \& Zavatti, M. 2008; Mendes, V. et al. 2008; Yang, J.Y. et al. 2008; Choi, J.M. et al 2009)

The most abundant prenylflavonoid, in hop, is the chalcone xanthohumol (XN), which can represents up to $1 \%$ in dry hop cones. Xanthohumol can be converted to the prenylflavanone isoxanthohumol (IX) in consequence of thermal treatment and increased $\mathrm{pH}$ value, being the main prenylflavonoid present in beer (Stevens, J.F. \& Page, J.E. 2004; Stevens, J.F. et al. 1999) Also other chalcones, occurring 10-100 fold lower concentrations than that of $\mathrm{XN}$, i.e. desmethylxanthohumol (DMX), isomerizes to 
the corresponding flavanones. Thus, DMX, considered as the precursor of the most flavonoids present in hop, gives a 1:1 racemate 6-prenylnaringenin (6-PN) with 8prenylnaringenin $(8-\mathrm{PN})$, which has been found to be the most potent phytoestrogen described until now (Zanoli, P. \& Zavatti, M. 2008; Chadwick, L.R. et al. 2006). Further the chemistry, under physiological conditions, 8-PN derives from IX through activation by intestinal microflora (Possemiers, S. et al. 2008) or by liver cytochrome P450 (Guo, J. et al. 2006).

Isoxanthohumol, besides to be the direct precursor of a potent phytoestrogen in diet, it has been suggested to have anti-inflammatory properties (Young-Chang, C. et al. 2010; Jeong Ho, J. et al. 2010). It's great potential as functional ingredient justifies any effort for its obtention and isolation. Nowadays, different processes have been described to extract prenylflavonoids such as $\mathrm{XN}$ from plant materials, based on the use of supercritical fluids (Biendl, M. et al. 2005), as well as on solvent pH adjustment (Ono, M. et al. 2009). On the other hand, different approaches have been depicted for the synthesis of 8-PN from IX, such as demethylation procedures by treatment with scandium trifluoromethanesulfonate and potassium iodide with an effectiveness of $92 \%$ (Wilhelm, H. \& Weesjohann, L.A. 2006) or demethylation of IX into 8-PN by the action of Eubacterium limosum with similar results to those of chemical synthesis (Possemiers, S. et al. 2009) but, to our knowledge, no process has been developed to selectively extract IX from natural sources.

Extraction of chemicals from plant material has usually been accomplished by conventional extraction processes such as solid-liquid extraction employing methanol, ethanol, hexane and acetone and also through steam distillation. Recently, there has 
been an increasing interest in the use of environmentally clean technologies able to provide high quality and high activity extracts while precluding any toxicity associated to the solvents. In this sense, technologies such as PLE (Pressurized Liquid Extraction), where pressure is applied to allow the use as extraction solvents of liquids at temperatures greater than their normal boiling point, meet the requirements to be considered clean and safe process. Among them, ASE (Accelerated Solvent Extraction), Pressurized Hot Water Extraction (PHWE) or SWE (Subcritical Water Extraction) are promising techniques for food related uses (Mendiola, J.A. et al. 2007).

PLE (Pressurized Liquid Extraction, commercially named as ASE or Accelerated Solvent Extraction), processes normally uses temperatures around 100-200 ${ }^{\circ} \mathrm{C}$ and pressures around 6-12 MPa. When water is used in PLE its commonly named as Pressurized Hot Water Extraction (PHWE) or SWE (Subcritical Water Extraction) when working conditions are over $280^{\circ} \mathrm{C}$ and $1.6 \mathrm{MPa}$ (Mendiola, J.A. et al. 2007).

The increase on the extraction temperature can promote higher solubility of the chemicals by increasing both, solubility and mass transfer rate. Besides, the high temperatures decrease the viscosity and the surface tension of the solvents, which helps to reach areas of the matrices more easily, improving the extraction rate. Among the different properties of interest for an extraction process, the most useful is the change in the dielectric constant of the water with the temperature that leads the water to behave like an organic solvent; for instance, decreasing from 80 at room temperature till around 33 at $200^{\circ} \mathrm{C}$, becoming similar of that of methanol (Marín, F.R. et al. 2009). 
Hence, considering the bioactivities of hop's prenylflavonoids, and in particular those of IX, the goal of the present investigation was to study the selective extraction of IX through friendly environmental technologies such as PHWE (Pressurized Hot Water Extraction) and PLE (Pressurized Liquid Extraction). The extraction process has been evaluated in terms of antiinflammatory properties, their total phenolic composition and content in the most relevant prenylflavonoids.

\section{EXPERIMENTAL}

\subsection{Samples and chemicals}

Hops samples (Humulus lupulus L.) consisted of dried female inflorescences pellets obtained from S.A Española de Fomento de Lúpulo (León, Spain). Pellets were stored protected from light and air, under refrigeration until use. Cryogenic grinding of the sample was performed under liquid nitrogen (Air liquid, Madrid, Spain) at the time of use. Dimetilsulfoxide (DMSO), acetonitrile, hexane and methanol were from Labscan analytical sciences (Gilwice, Poland). Milli-Q water was produced in situ by using an Integral 5-MiliQ System (Millipore Corporation, Billerica, USA). Folin-Ciocalteau`s reagent, gallic acid, sodium carbonate and sea sand were from Panreac Química Sau (Barcelona, Spain). Formic acid was from Sigma-Aldrich Química SA (Madrid, Spain). Reference samples or standards of Xanthohumol and Isoxanthohumol were from Sigma-Aldrich (St Louis, USA). To determinate anttinflamatory activity Human THP-1 monocytes cell line from American Type Culture Collection (ATCC, Teddington, Middlesex, UK) were use. LDLs were donated by Servicio de Bioquímica e Investigación, Hospital Ramón y Cajal (Madrid, Spain).

\subsection{Solid-liquid extraction}


The solid-liquid extraction was used as a control method to determine the total amount of XN and IX. The extraction procedure was as follows: cryogenically crushed hops were mixed with DMSO (1 g hop/40 mL of DMSO) and left in agitation at room temperature, for 24 hours in darkness. Samples were filtered and the cake obtained underwent the same process; this was repeated with fresh DMSO until no XN nor IX were detected in the extract.

\subsection{Pressurized liquid extractions}

To perform the extractions, an Accelerated Solvent Extraction system ASE 200 equipped with a solvent controller unit from Dionex Corporation (Sunnyvale, CA, USA) was used. Two different extraction procedures have been used depending if individual extraction (at a selected temperature with water or ethanol) or sequential experiments were performed. All extractions were carried out using $11 \mathrm{~mL}$ extraction cells, containing $1 \mathrm{~g}$ of sample mixed with $2 \mathrm{~g}$ of sea sand.

Water extractions were performed using a pressure of $1500 \mathrm{psi}$ (10.68 $\mathrm{MPa}$ approximately) at the following temperatures: $50^{\circ} \mathrm{C}, 100^{\circ} \mathrm{C}, 150^{\circ} \mathrm{C}$ and $200^{\circ} \mathrm{C}$; extraction time was 30 min (6 cycles of 5 minutes each one). For comparison, ethanol extraction at $150^{\circ} \mathrm{C}$ was also performed for 30 minutes (6 cycles of 5 minutes each one).

Sequential extractions were carried out with the same sample using solvent in growing polarity order; hexane, ethanol and finally water at $150^{\circ} \mathrm{C}(10.68 \mathrm{MPa})$ for 20 min. each fraction. The extraction procedure was as follows: 1 . Sample and sea sand are loaded into cell, 2. Cell is filled with solvent up to pressure of $10.68 \mathrm{MPa}, 3$. Initial heat-up time is applied, 4. Static extraction with all system valves closed is performed without stirring (for 30 or 20 minutes, depending if individual or sequential extraction 
were carried out), 5. Cell is rinsed, 6. Solvents are purged from cell with $\mathrm{N}_{2}$ gas, 6 . Finally depressurization takes place.

Extracts were stored dried at $4^{\circ} \mathrm{C}$. Ethanol and hexane were evaporated using a rotary evaporator R-210 (from Büchi Labortechnik AG, Flawil, Switzerland). Water was removed by freeze drying (Freeze Dry System, Model 79 480, Labconco Corporation, Missouri, USA).

\subsection{HPLC-DAD}

Subcritical water extracts at four different temperatures $\left(50^{\circ} \mathrm{C}, 100^{\circ} \mathrm{C}, 150^{\circ} \mathrm{C}\right.$ and $200^{\circ} \mathrm{C}$ ) were analyzed by using the method describes by Bernal et al (2011). An Agilent Technologies (Palo Alto, CA, USA) 1100 series HPLC system coupled to a diode array detector (DAD) was used. Samples were dissolved in DMSO at a concentration of 10 mg/mL. An ODS2 Spherisorb C18 $80 \AA 5 \mu \mathrm{m}(250$ x 4.0 mm i.d.) column from Waters (Milford, MA, USA) was used.

The mobile phase consisted of (A) $1 \%$ acetic acid in acetonitrile (B) $1 \%$ acetic acid in water and (C) $1 \%$ acetic acid in methanol in a gradient-elution analysis programmed as follows: $0 \mathrm{~min}, 44 \% \mathrm{~B} 0 \% \mathrm{C}$; 0-10 min, 51\% B 5\% C; 10-12 min, 44\% B $0 \% \mathrm{C}$; with $5 \mathrm{~min}$ of post time at a flow rate of $1 \mathrm{~mL} / \mathrm{min}$. The column temperature was set at $25^{\circ} \mathrm{C}$ and the injection volume was $20 \mu \mathrm{L}$. The detection wavelengths were set at $370 \mathrm{~nm}$ for $\mathrm{XN}$ and $280 \mathrm{~nm}$ for IX and 8-PN, respectively.

\subsection{HPLC-MS/MS analysis of the extracts}

\subsubsection{Analytical conditions}

Analyses of individual extracts obtained using water and ethanol at $150^{\circ} \mathrm{C}$ and sequential extracts with hexane, ethanol and water were performed with an Accela 
(Thermo Electron Corporation; San Jose, CA) equipped with an ACE 3 C18-AR column 150 x $4.6 \mathrm{~mm}, 3 \mu \mathrm{m}$ particle size (Advanced Chromatography Technologies, Aberdeen, UK). Extracts were injected $(20 \mu \mathrm{l})$ in a concentration equal to $2.5 \mathrm{mg} / \mathrm{mL}$ of DMSO. The mobile phase was a mixture of solvent A (1\% formic acid in acetonitrile), B (1\% formic acid in methanol), C (1\% formic acid in water) and D (methanol) according to the step gradient shown in Table 1, lasting $32 \mathrm{~min}$. Flow rate was 0.6 $\mathrm{mL} / \mathrm{min}$. Detection was accomplished by using a mass spectrometer (triple quadrupole) (TSQ-Quantum, Thermo Electron Corporation, San Jose, CA) with an ESI (Electrospray Ionization) interface.

Spray voltage was set in $4500 \mathrm{~V}$ in negative mode. Mass analyzer was set simultaneously in full scan and MRM (Multiple Reaction Monitoring) modes, in this case MRM experiments were done using 1 precursor ion and 2 daughters as recommended by UE regulation (Commission Decision 657/2002 about performance of analytical methods and the interpretation of results). MRM filters were set for a better quantification of prenylflanoids. First quadrupole filtered $355,4 \mathrm{~m} / \mathrm{z}\left(\mathrm{M}+\mathrm{H}^{+}\right.$ion corresponding to XN and IX), MRM transitions were chosen automatically among the two most abundant by direct infusion 179 y $299 \mathrm{~m} / \mathrm{z}$, both compounds produced the same daughter ions using 28 and $16 \mathrm{~V}$ as collision energy respectively. Moreover another $\mathrm{m} / \mathrm{z}$ filter in the last part of the chromatogram to analyze unknown molecules, this filter was full scan $\mathrm{MS}^{2}$ which used $30 \mathrm{~V}$ for fragmentation.

\subsubsection{Method validation}

Standards of XN and IX were used to develop and validate the HPLC method. Validation was carried out following the ICH guidelines (1996) and IUPAC technical 
report of 2002 (Thompson, M. et al. 2002) determining selectivity, limits of detection and quantitation, linearity, precision and trueness.

The reproducibility of the analytical method was performed on a sample containing $1.25 \mu \mathrm{g} / \mathrm{mL}$ of IX at different days and different elapsed assay times. The linearity of response was determined by preparing solutions containing $0,0.125,1.25$, 1.562, 3.125, 12.5 and $25 \mu \mathrm{g} / \mathrm{mL}$ of $\mathrm{XN}$ or IX in methanol. LOD and LOQ were obtained according to the above cited reports.

\subsection{Folin-Ciocalteu method to determine total phenols}

Total phenols were determined as described by Kosar et al. (2005) with a modification: methanol is replaced by DMSO due to the low solubility of the extracts in the other solvents. Freeze-dried samples, from PLE extractions, were dissolved in a solution of $5 \mathrm{~mL}$ of $1.3 \% \mathrm{HCl}$ in DMSO and the resulting mixture $(100 \mu \mathrm{L})$ was added to $2 \mathrm{~mL}$ of $2 \%$ aqueous sodium carbonate solution. After $3 \mathrm{~min}, 100 \mu \mathrm{L}$ of $50 \%$ FolinCiocalteu's reagent was added to the mixture. After 30 min standing, absorbance was measured at $750 \mathrm{~nm}$ using a microplate reader (Sunrise Remote, Tecan Austria GmbH, Grödig, Austria). Content of total phenols was calculated on the basis of the calibration curve of gallic acid.

\subsection{Anti-inflammatory activity}

Subcritical water extract at $150^{\circ} \mathrm{C}$ was selected to perform anti-inflammatory assays. Human THP-1 monocytes cell line were maintained in suspension in RPMI 1640 culture medium (ATCC) supplemented with 10\% FBS (GIBCO Invitrogen, Pasley, Scontland, UK), $100 \mathrm{U} / \mathrm{mL}$ penicillin (GIBCO), $100 \mathrm{mg} / \mathrm{mL}$ streptomycin 
(GIBCO), $0.05 \mathrm{mM} \beta$-mercaptoethanol (Sigma-Aldrich, St Louis, MO, USA) and $2 \mathrm{mM}$ L-glutamine (GIBCO), at a density of $3-9 \times 10^{5}$ cells $/ \mathrm{mL}$ at $37{ }^{\circ} \mathrm{C}$ in $5 \% \mathrm{CO}_{2}$ and air 95\%. Cells were discarded and replaced by frozen stocks every 15 passages.

For cell differentiation, cells were pelleted via centrifugation and assessed for viability using the Trypan-blue exclusion method (Tolnai, S. 1975). Viable cells were incubated with 12-myristate, 13-acetate (PMA) $100 \mathrm{ng} / \mathrm{mL}$ (Sigma-Aldrich) for $48 \mathrm{~h}$ in FBS free medium.

After differentiation, the cells were washed with PBS (Phosphate Buffered Saline is 137 $\mathrm{mM} \mathrm{NaCl}, 12 \mathrm{mM}$ Phosphate, $2.7 \mathrm{mM} \mathrm{KCl}, \mathrm{pH} 7.4$ ) and treated with or without $\mathrm{Cu}^{2+}$ oxidized LDLs (Steinbrecher, U.P. 1987) to activate or not inflammatory cell response and incubated with the subcritical water hop extract diluted in FBS free medium, for 24 hours at $37^{\circ} \mathrm{C}$ in $5 \% \quad \mathrm{CO}_{2}$. Aliquots were analyzed to determine secreted cytokines. Cytokines IL-10, IL-6 and TNF- $\alpha$ were quantified using ELISA kits from BD Biosciences (San José, CA, USA), according to the manufacturer's instructions. Briefly, $100 \mu \mathrm{L}$ of 1:10 diluted medium was added to anti-cytokine antibody coated polystyrene wells and incubated for $2 \mathrm{~h}$. After washing, the plates were incubated with biotin-labeled secondary antibody for 1 hour. The plates were washed and incubated for $30 \mathrm{~min}$ in the dark with substrate solution. Stop solution was added and the absorbance read at 450 nm. Indomethacin (a non steroidal anti-inflammatory drug) at pharmacological doses was used as a control. Standard IX, at the same amount that present in the subcritical water extract (per gram), was also tested to correlate the anti-inflammatory action to the presence of this compound.

\section{RESULTS AND DISCUSSION}




\subsection{Pressurized Hot Water Extraction}

In order to optimize the effects of PHWE of hops four extraction temperatures were tested: $50^{\circ} \mathrm{C}, 100^{\circ} \mathrm{C}, 150^{\circ} \mathrm{C}$ and $200^{\circ} \mathrm{C}$. In Table 2 are shown the obtained results in terms of yield (\% dry weight) and concentration factor of the total amount of IX, XN and 8-PN, quantified by HPLC-DAD according to Bernal et al (2011).

The results indicate that in extractions with pressurized water, as described in material and methods, the yield increases with temperature. Thus, temperatures over the boiling point, when the effect of pressure is noteworthy, lead to step up the yield in $50 \%$, approximately, respect to the extractions performed below, or at, $100^{\circ} \mathrm{C}$. In a similar way, as shown in Table 2, it is observed a clear rise in the amount of the quantified prenylfalvonoids (IX, XN) with the temperature of extraction, being the effect of pressure clearly noticeable when extractions are performed at higher temperatures, i.e. $150^{\circ} \mathrm{C}$ and $200^{\circ} \mathrm{C}$. For the formers, the prenylflavonoids are threefold respect the extraction performed at $100^{\circ} \mathrm{C}$, and more than thirtyfold when compared with the obtained results at $50^{\circ} \mathrm{C}$. The concentration factor as well as the extraction yield of prenylflavonoids was lower at $200^{\circ} \mathrm{C}$ than at $150^{\circ} \mathrm{C}$, these results it might be due to degradation of these compounds at the highest temperatures. Nevertheless, the differences were not statistically significant (Table 2). Furthermore, together with the aforementioned parameters it seems advisable to take into consideration others such as selectivity. To this respect, the chalcone xanthohumol is detected at all the studied temperatures while its derivative, the flavanone isoxanthohumol, is only detected at the higher temperatures, i.e. at $150^{\circ} \mathrm{C}$ and $200^{\circ} \mathrm{C}$. On the other hand, some clogging problems were observed at $200^{\circ} \mathrm{C}$, together with a more motley chromatographic 
profile, that revealed new compounds do not detected at $150^{\circ} \mathrm{C}$ and for those new ones the HPLC-DAD used method was not useful to identify (Figure 1).

The exposed results lead to select the extraction performed at $150^{\circ} \mathrm{C}$ as the most convenient. However, at this point, a more complete characterization of the extracts and more accurate quantification of phytoestrogens were needed. Thus, a new HPLCMS/MS method was developed to analyze and quantify phytoestrogens in hop's extracts. Use of MS allowed also the identification of several other compounds that could also contribute, to some extent, to the biological activities, below described, of the extracts. In fact the mass analyzer used was a triple quadrupole, which is designed to obtain a high accuracy in quantitative analysis.

Validation of the LC-MS/MS method was carried out according to material and methods as described in section 2.4.2. Standards of IX and XN showed a retention time of $4.5 \mathrm{~min}$ and $14.7 \mathrm{~min}$, respectively, with a relative standard deviation (RSD) lower than $2 \%$. The LOD and LOQ obtained were: $0.064 \mu \mathrm{g} / \mathrm{mL}$ and $0.07 \mu \mathrm{g} / \mathrm{mL}$ for IX and $0.008 \mu \mathrm{g} / \mathrm{mL}$ and $0.01 \mu \mathrm{g} / \mathrm{mL}$ for $\mathrm{XN}$. The linearity was maintained in the concentration range of $0.07-3.25 \mu \mathrm{g} / \mathrm{mL}(\mathrm{r}=0.998)$ for $\mathrm{IX}$ and $0.01-3.125 \mu \mathrm{g} / \mathrm{mL}$ for $\mathrm{XN}(\mathrm{r}=0.993)$. In terms of reproducibility, the RSD value of intraday and interday analysis was lower than $2 \%$ (1.6\% for intraday and $1.7 \%$ for interday analysis).

In order to compare these concentrations with total amount of $\mathrm{XN}$ and IX present in hop, a series of extractions with DMSO were done until hop was exhausted. These extractions were carried out using mild conditions (agitation in dark, at room temperature) to avoid isomerization and degradation. The analytical results showed 
contents in xanthohumol near to six fold than isoxanthohumol, with average values of $0.67 \mathrm{mg} / \mathrm{g}$ of dry hop and $3.93 \mathrm{mg} / \mathrm{g}$ of dry hop, for IX and $\mathrm{XN}$ respectively; being these amounts within standard content for IX and XN in hop pellets and cones (Magalhaes, P.J. et al. 2007; Kac, J. et al. 2007).

On the other hand, when PHWE hop's extract (obtained at $150^{\circ} \mathrm{C}$ ) was analyzed by HPLC-MS/MS were found values of $2.34 \mathrm{mg} / \mathrm{g}$ and $0.11 \mathrm{mg} / \mathrm{g}$ for IX and XN, respectively. It is worthwhile to notice that the ratio IX/XN rises from 0.17 , in pellets, to 21 , in the extract, which represents near to 124 fold increases. The selectivity in the extraction will be discussed below, by comparing with other solvents, and may include isomerization from XN to IX as described in the literature (Stevens, J.F. \& Page, J.E. 2004; Magalhaes, P.J. et al. 2007).

\subsection{Pressurized Liquid Extraction}

To compare a possible better fit of PHWE, for IX extraction, with other PLE technologies ethanol and a sequence of three solvents (hexane, ethanol and water) were used. Ethanol was one of the first solvents used in the beginning of the last century for the extraction of aromatic and bitter components from hop. Ethanol is a very strong solvent with low selectivity, extracting a bunch of compounds (e.g. lupulin components, plant pigments, cuticular waxes, etc) further than flavonoids. On the other hand, a sequence of solvents, as described above, should extract in a first step (hexane) those compounds of lowest polarity, such as terpenes, waxes and bitter acids; cleaning the extraction cake for further extractions with more polar solvents, ethanol or water, more suitable for flavonoids, at least under PLE conditions. 
In Table 3 are shown the contents (mg/g extract) in IX and $\mathrm{XN}$ for the different extractions. The use of ethanol as solvent, in PLE, yields ca. $0.67 \mathrm{mg} / \mathrm{g}$ and $1.89 \mathrm{mg} / \mathrm{g}$ of IX and $\mathrm{XN}$ respectively, with a ratio (IX/XN) of 0.35. These data show that ethanol, under these conditions, do not provide any selectivity, regarding to IX extraction. The obtained ratio IX/XN (0.35) is, by contrast with other extractions, similar to the hop pellets $(0.17)$. On the other hand, regarding to its usefulness to extract $\mathrm{XN}$, the yield in prenylflavonoids is in the range of 30 fold lower than the commercial ethanolic extracts from hop cones (Magalhaes, P.J. et al. 2007). However, other approached such as He et al. (2005) showed through SFE (Supercritical Fluid Extraction) conditions and with ethanol as modifier in ranges of $80-100 \%$ showed better results, when measure gross flavonoids, and similar than PLE-EtOH-2 ${ }^{\text {nd }}$ extract(Pressurized Liquid Extraction using EtOH as solvent, after using hexane) (He, G.C. et al. 2005), as seen below.

When an alternative strategy is used, i.e. a sequential extraction where solvents were used in order of increasing polarity (first hexane, later ethanol and finally water) yields did not improve. As shown in Table 3 the amount of IX and XN extracted with hexane $\left(1^{\text {st }}\right.$ extraction) and water $\left(3^{\text {rd }}\right.$ extraction $)$, under our conditions, was negligible in comparison with other solvents (PHWE, PLE-EtOH, PLE-EtOH-2 ${ }^{\text {nd }}$ ). However, PLEEtOH-2 ${ }^{\text {nd }}$ extraction gave the highest yield with ca. $5 \mathrm{mg} / \mathrm{g}$ and ca. $2 \mathrm{mg} / \mathrm{g}$ of extract for IX and $\mathrm{XN}$, respectively, although with low selectivity towards IX such as the ratio IX/XN shows. From a practical point of view such strategy can be discharged, however some interesting observations can be done. Thus, it should be notice that the ratio IX/XN increases with solvent polarity and that even in the extraction with hexane this one is higher than the ratio of the raw material; which can be explained by the effect of 
$\mathrm{P}$ and T, favouring the isomerization of XN into IX (Stevens, J.F. \& Page, J.E. 2004;

Stevens, J.F et al. 1999).

As can be seen in Table 3 and Figure 2, comparing the different extraction methods, the selectivity of these processes has notable variations. In this sense, the selectivity, regarding to IX, of water under pressurized hot water conditions was, as previously mentioned, much higher than the sequential extraction and the individual extraction with pressurized ethanol. In fact, the pressurized water extraction at $150^{\circ} \mathrm{C}$ showed a high selectivity towards IX, increasing the ratio IX/XN 124 times, yielding an extract notably different regarding to the obtained with DMSO by solid-liquid extraction (used here as a reference method until sample exhaustion). The selective increase in IX against $\mathrm{XN}$ it could be tried to explain by the change in polarity solvent occurred in water during PLE (Mendiola, J.A. et al. 2007; Marín, F.R et al. 2009) However, due to the very slight differences in solubility between chalcones (e.g. xanthohumol) and flavanones (e.g. isoxanthohumol) (Markham, K.R. 1982) it seems a more elegant explanation an isomerization from $\mathrm{XN}$ into IX, which is produced at high temperatures, and also is favored by the high pressures used in PLE (Stevens, J.F. \& Page, J.E. 2004; Magalhaes, P.J. et al. 2007).

\subsection{Other compounds}

In Figure 2 is shown a qualitative chromatographic profile of the different extracts. As can be see, with the selected filter, no other prenylflavonoids seem to be present in the extracts. However, together with a low amount of prenylflavonoids there are present many other compounds that can perform any biological activity. To this 
respect we centered our efforts in evaluate the content of phenols and the presence of bitter acids.

The Folin-Ciocalteu analysis of hops extracts revealed the presence of phenolics in all of them, with the highest content in the hexane fraction (sequential extraction), being irrelevant the content in prenylflavonoids. On the other hand, the extract obtained by PHWE and both ethanolic extracts showed the highest relative amount in prenylflavonoids (see Figure 3). Phenolic compounds show a very limited or negligible solubility in hexane (Markham, K.R. 1982), which lead to explain the results by some kind of interaction in Folin reaction, as described in the literature (Box, J.D. 1983), which could be due to any phenolic terpenes or bitter acids.

On the other hand, chemical characterization of extracts resulted on the identification of compounds other than prenylflavonoids. Those compounds were detected in both ethanolic extracts as well as in the hexane fraction. These non-polar compounds appear in the last part of the chromatogram (less polar) at retention times ranging from 16.9 to $20.3 \mathrm{~min}$ (Figure 4); they were identified as bitter acids, using their characteristic parameters (molecular weight and UV spectra) which are shown in Table 4. Among them were identified humulone and its different isoforms corresponding to $\alpha$ acids and colupulone and its different isoforms, corresponding to $\beta$-acids. The presence of bitter acids in these extracts is consistent with the polarity of the used solvents such as hexane and ethanol.

\subsection{Anti-inflamatory activity}


Considering the selectivity, regarding IX, of PHWE extracts at $150^{\circ} \mathrm{C}$, and attending to the anti-inflammatory properties described for prenylflavonoids (Zanoli, P. \& Zavatti, M. 2008; Stevens, J.F. \& Page, J.E. 2004) the extracts underwent an in vitro anti-inflammatory test as described in material and methods. For this, two cytokines with proinflammatory activity (TNF- $\alpha$, IL-6) and one with anti-inflammatory activity (IL-10) were measured and compared to a control sample (Parkin, J. \& Cohen, B. 2001; Finch, C.E. 2011). As shown in Figure 5, the treatment with indomethacin (treatment 2) showed a decrease of the secretion of proinflammatory cytokines (TNF- $\alpha$ and IL-6), and a slight increase in the anti-inflammatory cytokine IL-10 of ca. $20 \%$ respect to the control. Results of treatment 4 (IX in equal concentration of PHWE extract) did not show significant changes, when compared with control, for the production of cytokine IL-10 (anti-inflammatory). However, production of proinflammatory cytokines was lower than in the control. Finally, PHWE extract showed similar production of cytokines IL-10 and TNF- $\alpha$ that indomethacin, which may indicates some kind of antiinflammatory activity based on the indomethacin activity. On the contrary, production of the proinflammatory cytokine IL-6 was only ca. $10 \%$ less than in control and about the double than the produced by indomethacin treatment.

It may be concluded that PHWE extract shows, to some extent, antiinflammatory activity based in the production of anti-inflammatory and proinflammatory cytokines, being stimulated its production for the first one and reduced for the other two. Furthermore, this anti-inflammatory activity cannot be explained by the activity of IX. Thus, treatment 4, which only contains IX, showed to be less effective, than PHWE extract an indomethacin, depressing the production of TNF- $\alpha$ or increasing the production of IL-10, but more effective regarding to IL-6. Therefore, the 
anti-inflammatory activity of PHWE extract may be higher than that of IX due to the contribution of other unidentified compounds present in the extract, such as phenolic or bitter acids.

\section{CONCLUSIONS}

In this work, it's been demonstrated the feasibility of a new environmentally friendly process, based on the use of subcritical water at $150^{\circ} \mathrm{C}$, to selectively isolate IX from hops. The extracted IX can be used as a precursor of 8-PN. The extraction method based in water, have proved to be more selective than process based on subcritical ethanol or sequential extraction with different solvents although the yield should be improved in further research. On the other hand the extract has demonstrated its capacity to increase the production of IL-10 and to decrease the production of TNF- $\alpha$ and IL-6, with a similar activity of a commercial drug used to treat the inflammatory processes.

\section{ACKNOWLEDGEMENTS}

This work has been funded by a CICYT Project (AGL2007-64198/ALI), CONSOLIDER INGENIO 2010 CSD2007-00063 FUN-C-FOOD (MEC) and ALIBIRD-CM 2010-2013 INGREEN.

\section{REFERENCES}


Bernal, J., Martinez García-Mauriño, C., Reglero, G., Cifuentes, A., Marín, F.R. \& Ibáñez, E. (2011). Fast screening method to determine hop's phytoestrogens. Food Analytical Methods, 4, 416-423.

Biendl, M., Becker, H. \& Nookandeh, A. (2005). Process for producing xanthohumol present in hops and xanthohumol-rich hop extract obtainable thereby. US Patent 6867332 B1.

Box, J.D. (1983). Investigation of the folin-ciocalteau phenol reagent for the determination of polyphenolic substances in natural waters. Water Research, 17, 511-525.

Chadwick, L.R., Pauli, G.F. \& Farnsworth, N.R. (2006). The pharmacognosy of Humulus lupulus L. (hops) with an emphasis on estrogenic properties. Phytomedicine, 13, 119-131.

Choi, J.M., Kim, H.J., Lee, K.Y., Choi, H.J., Lee, I.S. \& Kang, B.Y. (2009). Increased IL-2 rpoduction in T cells by xanthohumol through enhanced NF-AT and AP-1 activity. International Immunopharmacology, 9, 103-107.

Colgate, E.C., Miranda, C.L., Stevens, J.F., Bray, T.M. \& Ho, E. (2007) Xanthohumol, a prenylflavonoid derived from hops induces apoptosis and inhibits NF-kappaB activation in prostate epithelial cells. Cancer Letters (N. Y., NY, U. S.), 246, 201209.

Finch, C.E. (2011). Inflamation in aging processes: An integrative and ecological perspective. In E. Masoro \& S. Austad (Eds.), Handbook of the biology of aging (pp. 275-296). San Diego: Academic Press.

Guo, J., Nikolic, D., Chadwick, L.R., Pauli, G.F. \& Van Breemen, R.B. (2006). Identification of human hepatic cytochrome P450 enzymes involved in the 
metabolism of 8-prenylnaringenin and isoxanthohumol from hops (Humulus lupulus L.). Drug Metabolism and Disposition, 34, 1152-1159.

He, G.Q., Xiong, H.P., Chen, Q.H., Ruan, H., Wang, Z.Y. \& Traore, L. (2005). Optimization of conditions for supercritical fluid extraction of flavonoids from hops (Humulus lupulus L.). Journal of Zhejiang University-SCIENCE, 6B, 999-1004.

Jeong Ho, J., Ju Sun, K., Sam Sik, K., Kun Ho, S., Hyun Wook, C. \& Hyun Pyo, K. (2010). Anti-inflammatory and anti-arthritic activity of total flavonoids of the roots of Sophora flavescens. Journal of Ethnopharmacology, 127, 589-595.

Kac, J., Zakrajsek, J., Mlinaric, A., Kreft, S. \& Metk, F. (2007). Determination of xanthohumol in hops (Humulus lupulus L) by nonaqueous CE. Electrophoresis, 28, 965-969.

Koo, J.H., Kim, H.T., Yoon, H.Y., Kwon, K.B., Choi, I.W., Jung, S.H., Kim, H.U., Park, B.H. \& Park, J.W. (2008). Effects of xanthohumol on melanogenesis in B16 melanoma cells. Experimental and Molecular Medicine , 40, 313-319.

Kosar, M., Dorman, H.J.D. \& Hiltunen, R. (2005). Effect of an acid treatment on the phytochemical and antioxidant characteristics of extracts from selected Lamiaceae species. Food Chemistry, 91, 525-533.

Magalhaes, P.J., Guido, L.F., Cruz, J.M. \& Barros, A.A. (2007). Analysis of xanthohumol and isoxanthohumol in different hop products by liquid chromatography-diode array detection electrospray ionization tandem mass spectrometry. Journal of Chromatography A, 1150, 295-301.

Marín, F.R., Señorans, F.J., Reglero, G. \& Ibañez, E. (2009). Pressurized water in food industry. Implication on chemical and microbiological control in foods through 
extraction and oxidation. Obtention of rosemary antioxidant extracts as practical approach. In M.J. Cantalejo (Eds.), Agricultural and Food Chemistry (pp. 89-114). Kerala (India).

Markham, K.R. (1982). Techniques of flavonoid identification. London: Academic Press.

Mendes, V., Monteiro, R., Pestana, D., Teixeira, D., Calhau, C. \& Azevedo, I. (2008). Xanthohumol influences preadipocyte differentiation: Implication on antiprolifereative and apoptotic effects. Journal of Agricultural and Food Chemistry, 56, 11631-11637.

Mendiola, J.A., Herrero, M., Cifuentes, A. \& Ibañez, E. (2007). Uses of compressed fluids for simple preparation: Food applications. Journal of Chromatography A, $1152,234-246$.

Ono, M., Yamaguchi, N. \& Yamaguchi, K. (2009). Xanthohumol-enriched hop extract. US Patent 7833552 B2.

Parkin, J. \& Cohen, B. (2001). An overview of the immune system. Lancet, 357, 17771789.

Possemiers, S., Rabot, S., Espin, J.C., Bruneau, A., Philippe, C., Gonzalez-Sarrías, A., Heyerick, A., Tomás-Barberán, F.A., Keukeleire, D.D. \& Verstraete, W. (2008). Eubacterium limosum activates isoxanthohumol from hops (Humulus lupulus L) into the potent phytoestrogen 8-Prenylnaringenin in vitro and in rat intestine. Journal of Nutrition, 138, 1310-1316. 
Possemiers, S., Verstraete, W., Heyerick, A. \& De Keukeleire, D. (2009) Enzymathic demethylation of flavonoids. US Patent 20090130724.

Steinbrecher, U.P. (1987). Oxidation of human low density lipoprotein results in derivatization of lysine residues of apolipoprotein B by lipid peroxide decomposition products. Journal of Biological Chemistry, 262, 3603-3608.

Stevens, J.F. \& Page, J.E. (2004). Xanthohumol and related prenylflavonoids from hops and beer: to your good health!. Phytochemistry, 65, 1317-1330.

Stevens, J.F., Taylor, A.W. \& Deinzer, M.L. (1999). Quantitative analysis of xanthohumol and related prenylflavonoids in hops and beer by liquid chromatography tandem mass spectrometry. Journal of Chromatography A, 832, 97-107.

Thompson, M., Ellison, S.L.R. \& Wood, R. (2002). Harmonized guidelines for single laboratory validation of methods of analysis (IUPAC Technical Report). Pure and Applied Chemistry, 74, 835-855.

Tolnai, S. (1975). A method for viable cell count. Methods in Cell Science, 1, 37-38.

Wilhelm, H. \& Weesjohann, L.A. (2006). An efficient synthesis of the phytoestrogen 8prenylnaringenin from xanthohumol by a novel demethylation process. Tetrahedron Letters, 62, 6961-6966.

Yang, J.Y., Della-Fera, M.A., Rayalam, S. \& Baile, C.A. (2008). Enhanced effects of xanthohumol plus honokiol on apoptosis in 3T3-L1 adipocytes. Obesity, 16, 12321238. 
Young-Chang, C., Sung-Kyun, Y., Hyun Jung, K., Cheong-Weon, C., Ik-Soo, L. \& Bok Yun, K. (2010). Xanthohumol inhibits IL-12 production and reduces chronic allergic contact dermatitis. International Immunopharmacology, 10, 556-561.

Zanoli, P. \& Zavatti, M. (2008). Pharmacognostic and pharmacological profile of Humulus lupulus L. Journal of Ethnopharmacology, 116, 383-396. 
Figure 1. Chromatograms of pressurized hot water extractions at $50^{\circ} \mathrm{C}, 100^{\circ} \mathrm{C}, 150^{\circ} \mathrm{C}$ and $200^{\circ} \mathrm{C}, 370 \mathrm{~nm}$ signals shown, using the method described by Bernal et al ${ }^{20}$.

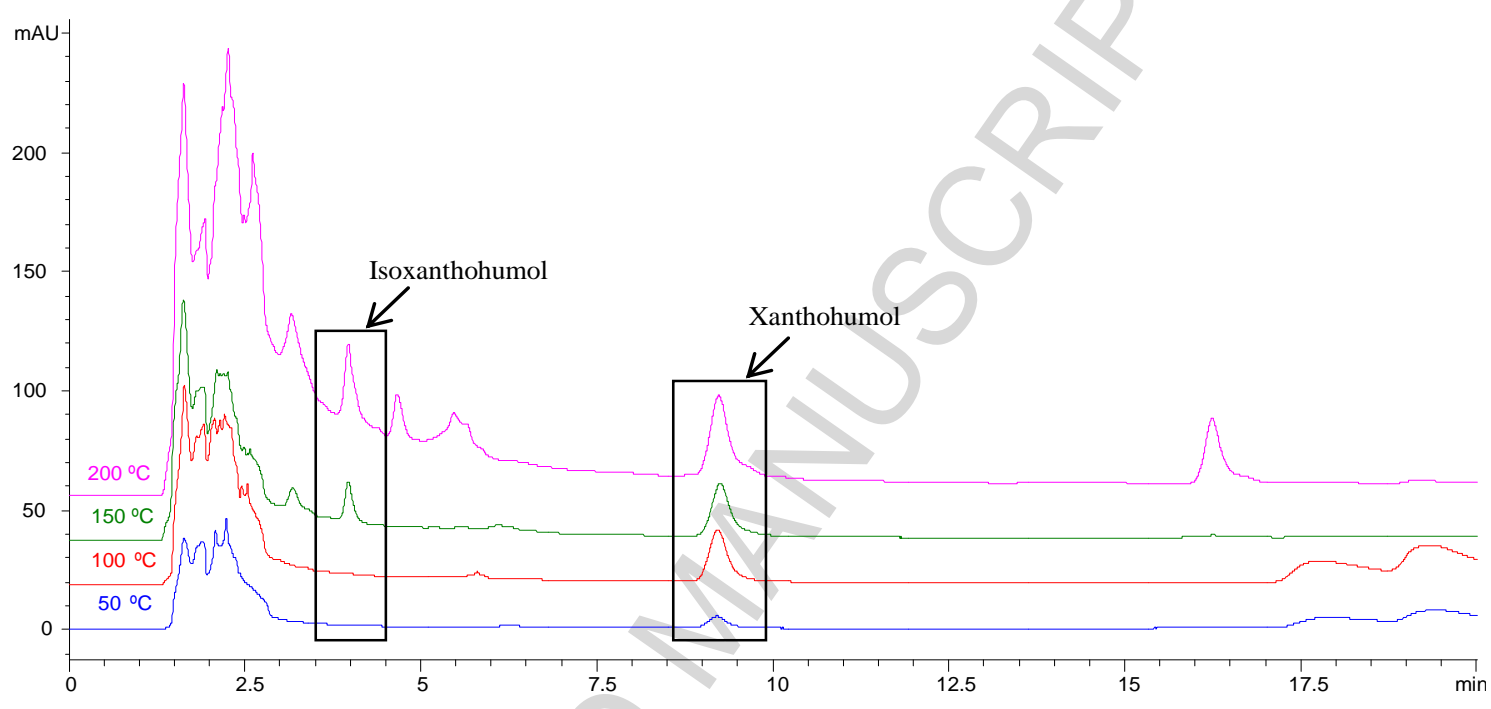


Figure 2. HPLC-MS/MS qualitative chromatographic profile of hop extracts, obtained by PHWE and PLE. MS filter set to analyze xanthohumol $(14.8 \mathrm{~min})$ and isoxanthohumol (4.5 min).

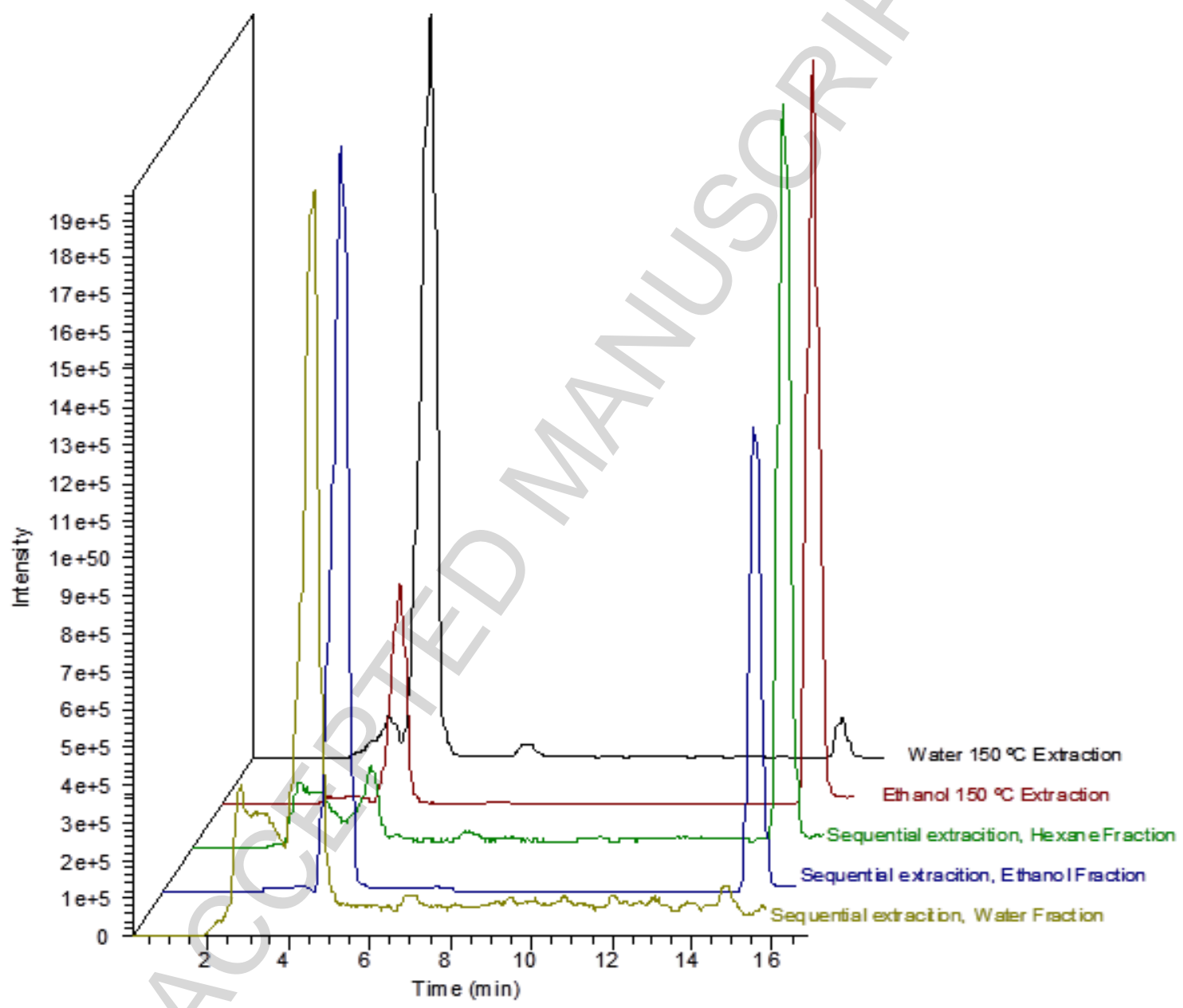


Figure 3. Total phenols (mg gallic acid/g extract) of the extracts obtained with different solvents under PLE conditions at $150^{\circ} \mathrm{C}$. PHWE (Pressurized Hot Water Extraction), PLE-EtOH (Pressurized Liquid Extraction using EtOh as solvent), PLE-Hexane-1 ${ }^{\text {st }}$ Ext. (Pressurized Liquid Extraction using hexane as solvent), PLE-EtOH- ${ }^{\text {nd }}$ (Pressurized Liquid Extraction using EtOH as solvent, after using hexane). PLE- $\mathrm{H}_{2} \mathrm{O}-3^{\text {rd }}$ (Pressurized Liquid Extraction using water as solvent, after using ethanol). The bars represent the total phenols and the grey area the proportion of prenylflavonoids.

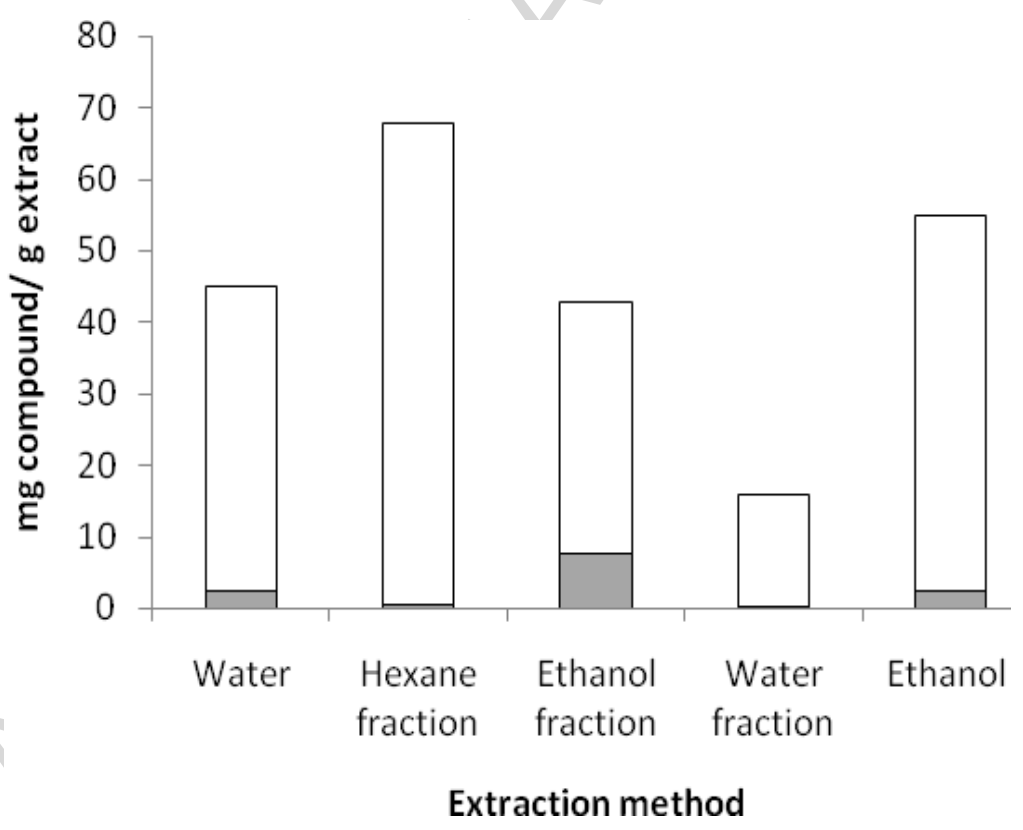


Figure 4. HPLC-MS/MS chromatographic profile of an ethanolic extract by PLE at $150^{\circ} \mathrm{C}$, obtained using full scan $\mathrm{m} / \mathrm{z}$ filter.

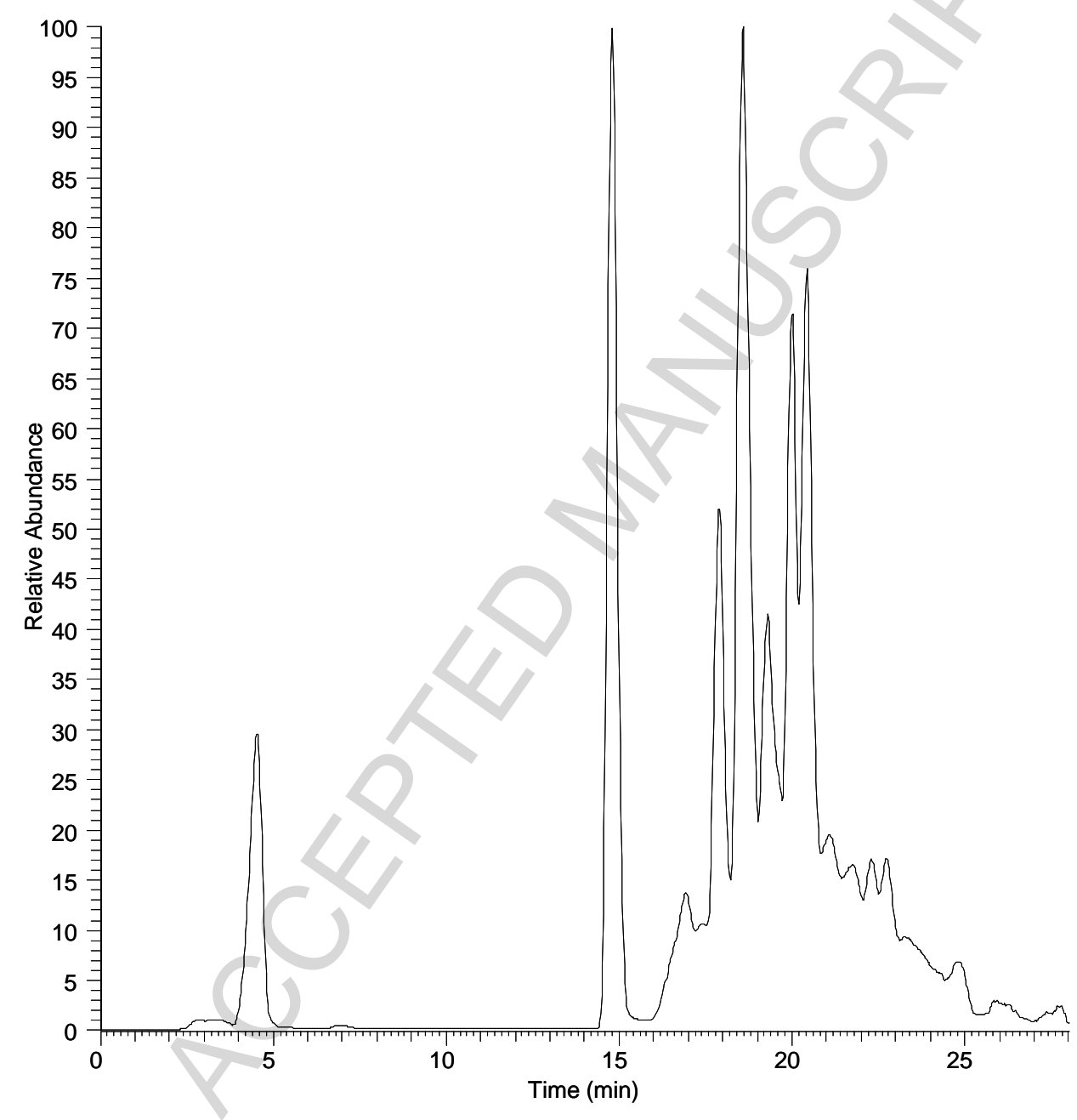


Figure 5. Comparative effect of the extract obtained by PHWE on the production of cytokines in macrophages. Treatments: 1 (Control with $\mathrm{Cu}^{2+}$ oxidized LDLs), 2 (Indomethacin $5 \mu \mathrm{g} / \mathrm{ml}$ ), 3 (PHWE extract at $150^{\circ} \mathrm{C} 0.01 \mathrm{mg} / \mathrm{mL}$ ) and 4 (Equivalent of the IX contained in the extract). Results showed $\pm \mathrm{SD}(\mathrm{n}=3)$.

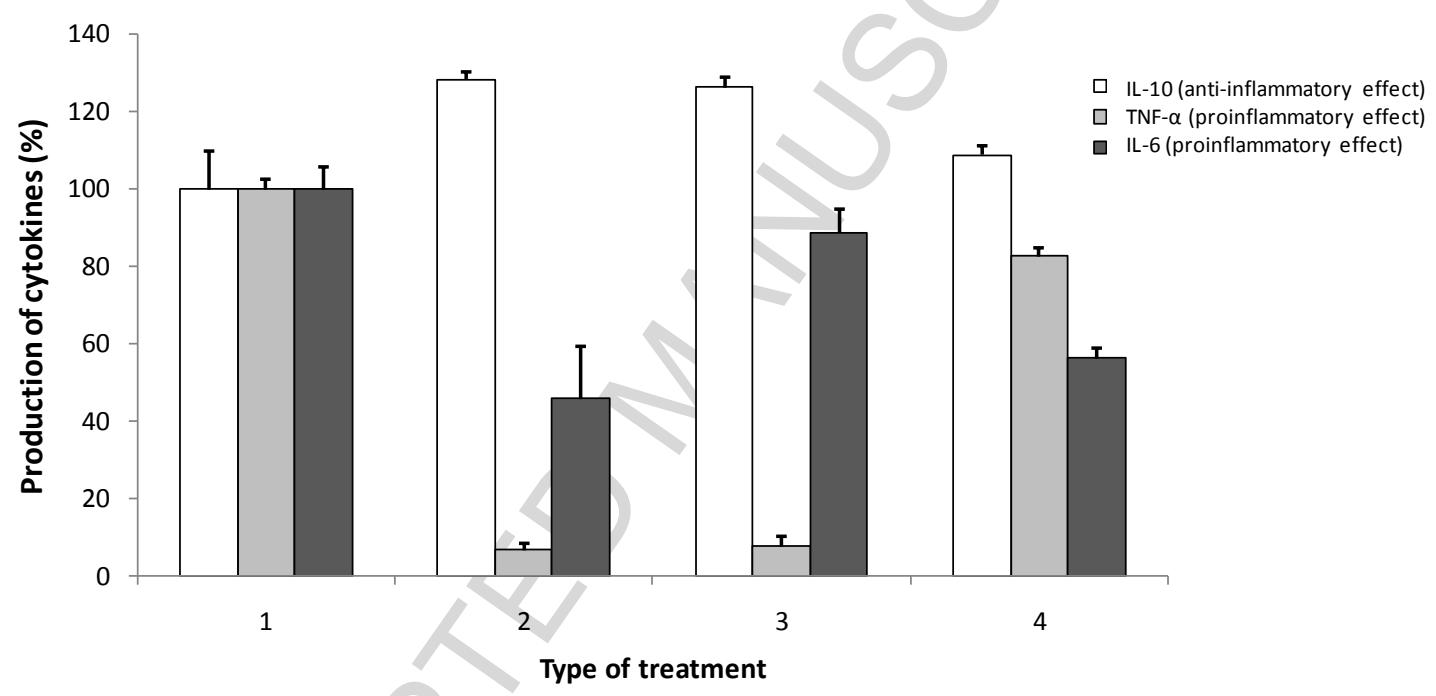


Table 1. Details of the step gradient used in the HPLC-MS method optimized and validated to characterize and quantify hops phytoestrogens.

\begin{tabular}{cccccc}
\hline Step & Time (min) & A\% & B\% & C\% & D\% \\
\hline 0 & 0 & 56 & 0 & 44 & 0 \\
1 & 8 & 51 & 5 & 44 & 0 \\
2 & 10 & 51 & 5 & 44 & 0 \\
3 & 17 & 95 & 5 & 0 & 0 \\
4 & 22 & 95 & 0 & 0 & 5 \\
5 & 26 & 80 & 0 & 0 & 20 \\
6 & 27 & 56 & 0 & 44 & 0 \\
7 & 32 & 56 & 0 & 44 & 0
\end{tabular}


Table 2. Data on extraction yield (\% of dry weight) of prenylflavonoids and concentration factor compared to the first extraction $\left(50^{\circ} \mathrm{C}\right)$.

\begin{tabular}{ccc}
\hline Extraction Temperature $\left({ }^{\mathbf{0}} \mathbf{C}\right)$ & Yield $^{(\%)}$ & Concentration factor \\
\hline 50 & 20.03 & 1.00 \\
100 & 22.10 & 9.81 \\
150 & 33.50 & 30.85 \\
200 & 31.64 & 30.24
\end{tabular}


Table 3. Contents of the flavanone isoxanthohumol (IX) and the chalcone xanthohumol $(\mathrm{XN})$ and ratio of $\mathrm{IX}$ respect to $\mathrm{XN}$ in extracts obtained by using different solvents under PLE conditions at $150^{\circ} \mathrm{C}$. PHWE (Pressurized Hot Water Extraction), PLE-EtOH (Pressurized Liquid Extraction using EtOH as solvent), PLE-Hexane- ${ }^{\text {st }}$ Ext. (Pressurized Liquid Extraction using hexane as solvent), PLE-EtOH-2 ${ }^{\text {nd }}$ (Pressurized Liquid Extraction using EtOH as solvent, after using hexane). PLE- $\mathrm{H}_{2} \mathrm{O}-3^{\text {rd }}$ (Pressurized Liquid Extraction using water as solvent, after using ethanol).

\begin{tabular}{lccc}
\hline Method of extraction & IX $^{\mathbf{a}}(\mathbf{m g} / \mathbf{g})$ & $\mathbf{X N}^{\mathbf{a}}(\mathbf{m g} / \mathbf{g})$ & Ratio IX/XN \\
\hline PHWE $_{(\mathrm{n}=3)}$ & $2.34 \pm 0.75$ & $0.11 \pm 0.03$ & 21 \\
PLE-EtOH $_{(\mathrm{n}=3)}$ & $0.67 \pm 0.10$ & $1.89 \pm 0.00$ & 0.35 \\
PLE-Hexane-1 $_{(\mathrm{n}=3)}^{\text {st }}$ & $0.07 \pm 0.04$ & $0.35 \pm 0.15$ & 0.20 \\
PLE-EtOH-2 $_{(\mathrm{n}=3)}^{\text {nd }}$ & $5.15 \pm 1.10$ & $2.57 \pm 0.33$ & 2 \\
PLE- $_{2} \mathrm{O}-3_{(\mathrm{n}=3)}^{\text {rd }}$ & $0.14 \pm 0.07$ & $0.01 \pm 0.0082$ & 14
\end{tabular}

${ }^{a}$ Data express average content in $\mathrm{mg} / \mathrm{g}$ of dry weight $\pm \mathrm{SE}$ 
Table 4. Characteristic parameters and identification of the compounds detected in ethanolic and hexane extracts whose retention times are included between 16.9 and 20.3 $\min$.

\begin{tabular}{|c|c|c|c|c|}
\hline $\begin{array}{l}\text { Retention } \\
\text { time(min) }\end{array}$ & $\begin{array}{l}\text { Spectra } \\
(\mathrm{nm})\end{array}$ & $\begin{array}{l}\text { Mass } \\
(\mathrm{m} / \mathrm{z})\end{array}$ & $\begin{array}{c}\text { Fragmentation } \\
(\mathrm{m} / \mathrm{z})\end{array}$ & Compound \\
\hline 14.7 & 380 & 354 & 233,119 & xanthohumol \\
\hline 16.9 & 274,346 & 362 & & $\begin{array}{l}\text { n-humulone } \\
\text { ad-humulone }\end{array}$ \\
\hline 17.8 & $\begin{array}{c}244,284 \\
322\end{array}$ & 348 & & iso-co-humulone \\
\hline 18.4 & $\begin{array}{c}324,284 \\
246\end{array}$ & 0 & & $\begin{array}{l}\text { iso-n-humulone } \\
\text { iso-ad-humulone }\end{array}$ \\
\hline 19.9 & 330 & 400 & 355 & colupulone \\
\hline 20.3 & 328,270 & & 369 & $\begin{array}{l}\text { n-lupulone } \\
\text { ad-lupulone }\end{array}$ \\
\hline
\end{tabular}


Figure 1. Chromatograms of pressurized hot water extractions at $50^{\circ} \mathrm{C}, 100^{\circ} \mathrm{C}, 150^{\circ} \mathrm{C}$ and $200^{\circ} \mathrm{C}, 370 \mathrm{~nm}$ signals shown, using the method described by Bernal et al ${ }^{20}$.

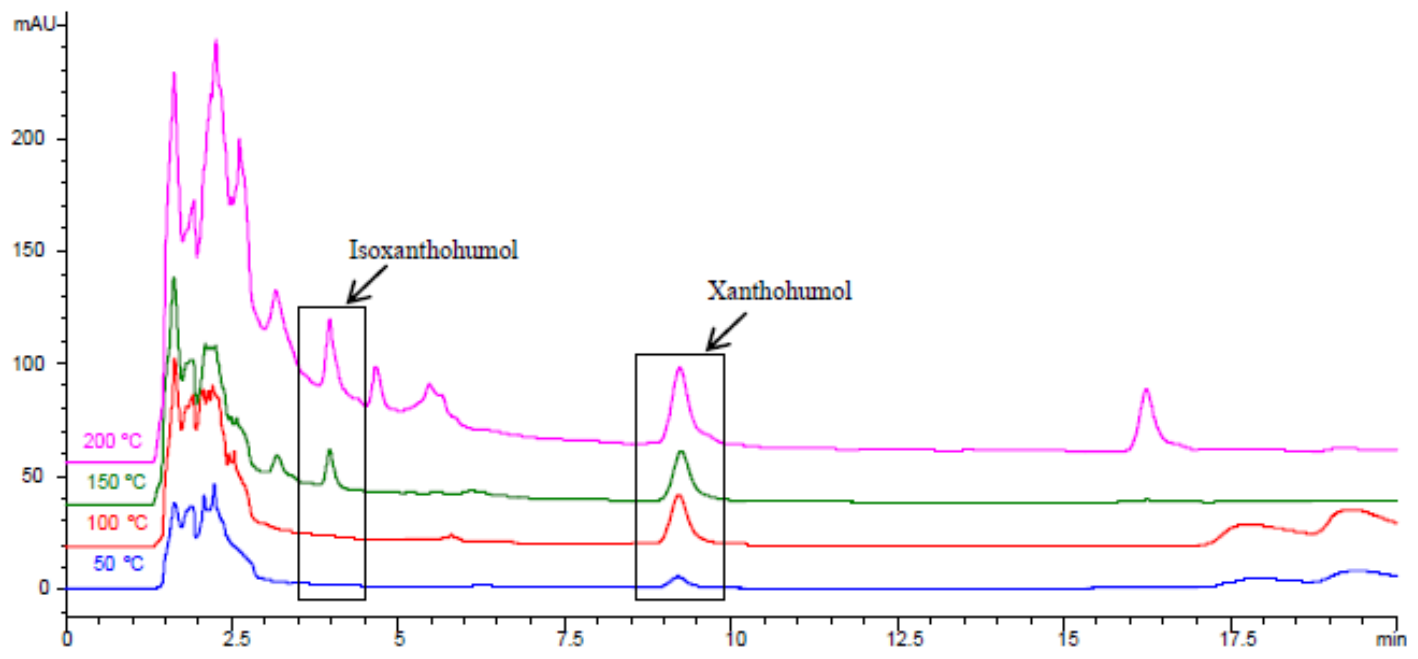


Figure 2. HPLC-MS/MS qualitative chromatographic profile of hop extracts, obtained by PHWE and PLE. MS filter set to analyze xanthohumol $(14.8 \mathrm{~min})$ and isoxanthohumol (4.5 $\mathrm{min})$.

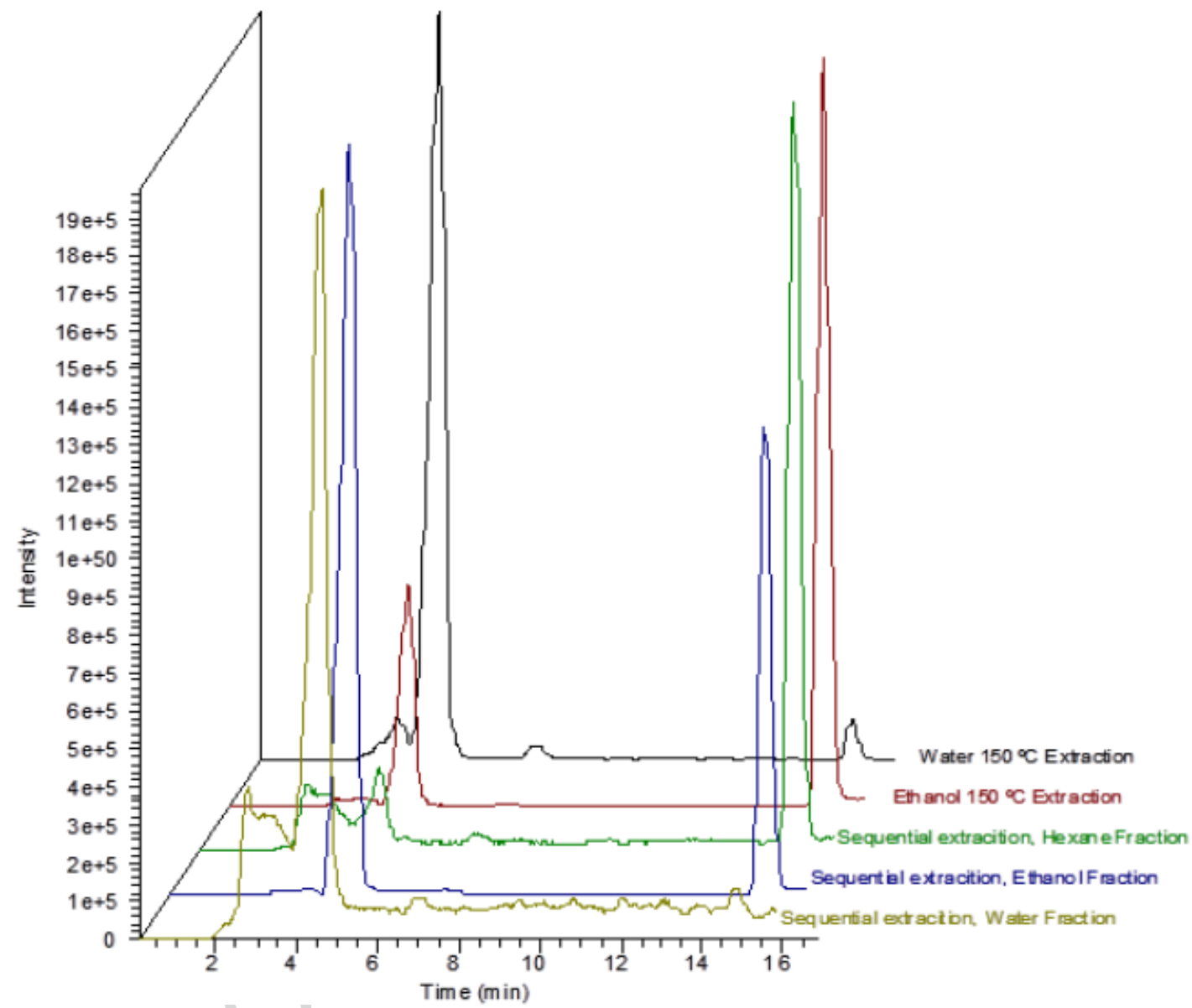


Figure 3. Total phenols (mg gallic acid/g extract) of the extracts obtained with different solvents under PLE conditions at $150^{\circ} \mathrm{C}$. PHWE (Pressurized Hot Water Extraction), PLE-EtOH (Pressurized Liquid Extraction using EtOh as solvent), PLE-Hexane- $1^{\text {st }}$ Ext. (Pressurized Liquid Extraction using hexane as solvent), PLE-EtOH-2 ${ }^{\text {nd }}$ (Pressurized Liquid Extraction using EtOH as solvent, after using hexane). PLE- $\mathrm{H}_{2} \mathrm{O}-3^{\text {rd }}$ (Pressurized Liquid Extraction using water as solvent, after using ethanol). The bars represent the total phenols and the grey area the proportion of prenylflavonoids.

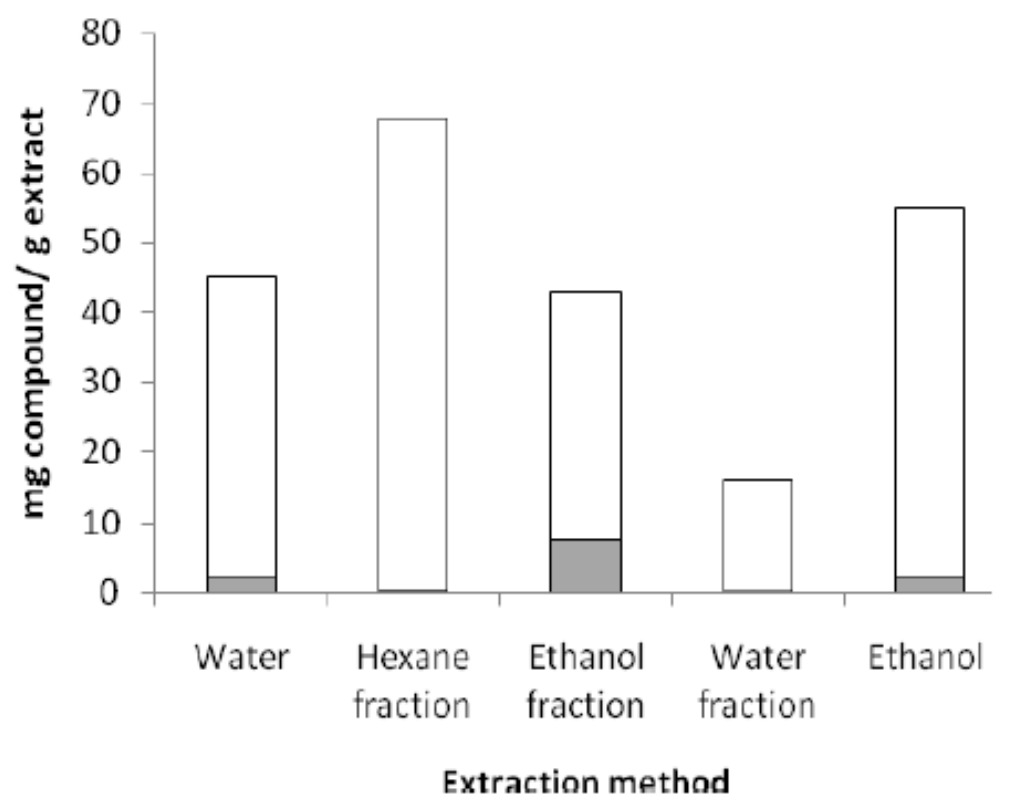


Figure 4. HPLC-MS/MS chromatographic profile of an ethanolic extract by PLE at $150^{\circ} \mathrm{C}$, obtained using full scan $\mathrm{m} / \mathrm{z}$ filter.

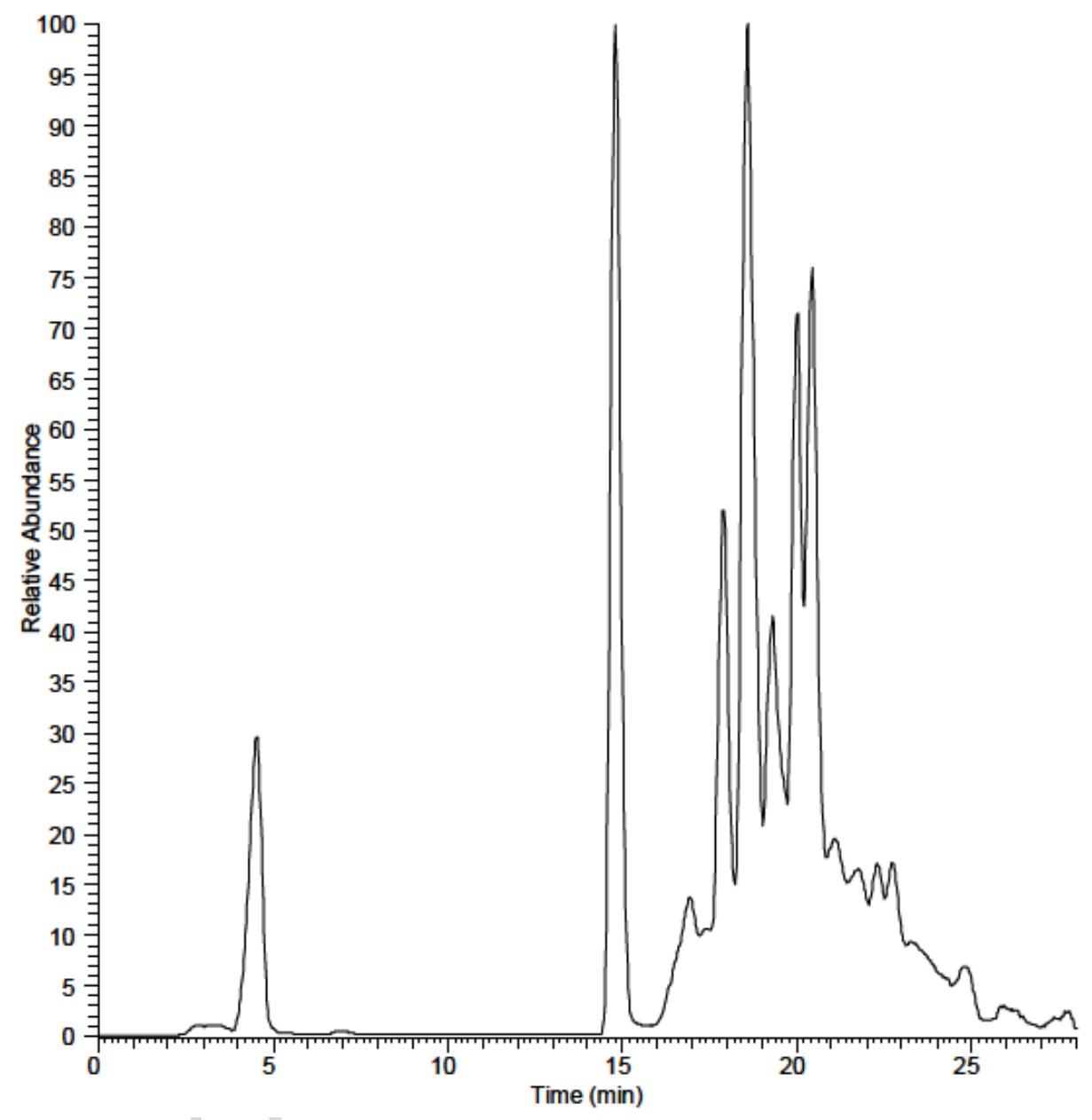


Figure 5. Comparative effect of the extract obtained by PHWE on the production of cytokines in macrophages. Treatments: 1 (Control with $\mathrm{Cu}^{2+}$ oxidized LDLs), 2 (Indomethacin $5 \mu \mathrm{g} / \mathrm{ml}$ ), 3 (PHWE extract at $150^{\circ} \mathrm{C} \quad 0.01 \mathrm{mg} / \mathrm{mL}$ ) and 4 (Equivalent of the IX contained in the extract). Results showed $\pm \mathrm{SD}(\mathrm{n}=3)$.

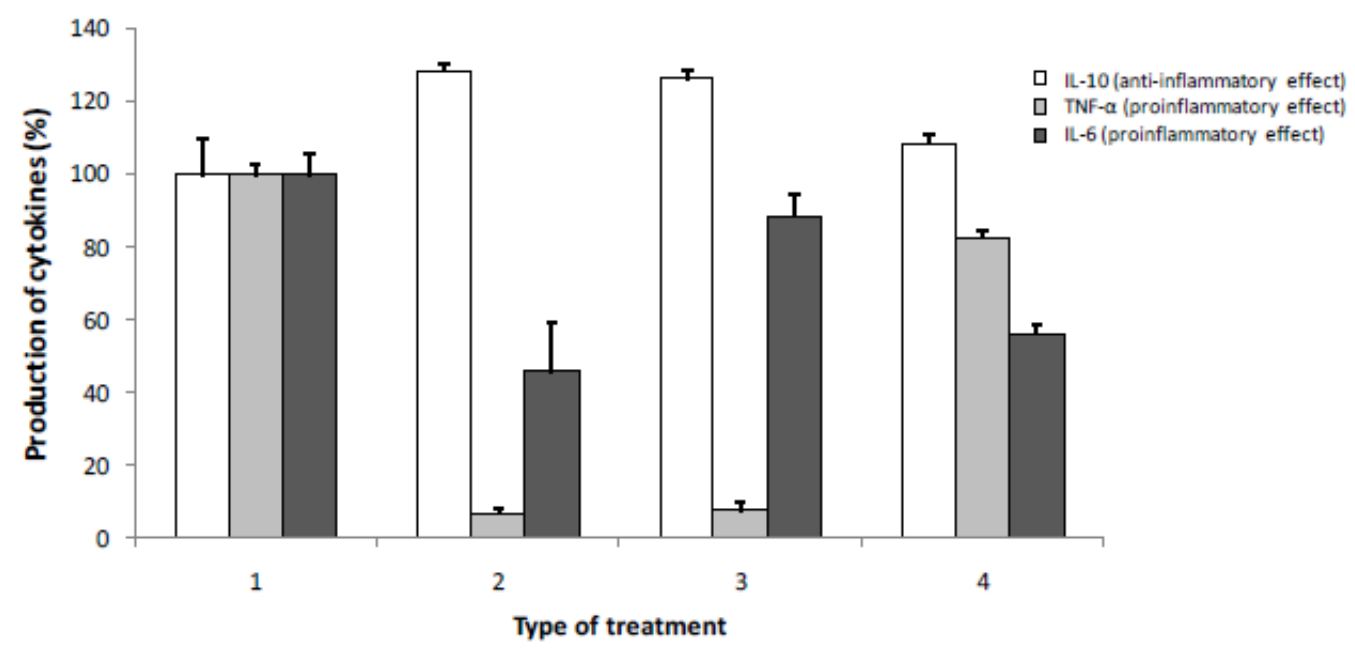




\section{Highlights}

- A hop extract enriched in Isoxanthohumol (IX) was obtained by using pressurized hot water extraction (PHWE) at $150^{\circ} \mathrm{C}$.

- Solid-liquid extractions shows high amount of Xantohumol (XN) against Isoxanthohumol while PHWE yield an inverted ratio of both compounds, may due to an isomerization between them.

- The PHWE extracts showed anti-inflammatory properties: increasing the production of IL-10 (anti-inflammatory effect) and decreasing the production of pro-inflammatory cytokines such as TNF- $\alpha$, being the activity similar of indomethacin (a non steroidal anti-inflammatory). 